\title{
Food Systems based on Life Cycle Assessment
}

\author{
Huainian Zhang ${ }^{a}$, Yinuo Fang ${ }^{b}$, Cheng Liang ${ }^{c}$, and Yinghong Guo ${ }^{d}$ \\ School of Beijing Institute of Petrochemical Technology, Beijing 100000, China \\ a 343137553@qq.com, b982150961@qq.com, c 2019311018@bipt.edu.cn, \\ d2019311018@bipt.edu.cn
}

\begin{abstract}
The food system is a complex social system. At present, international studies on food security evaluation indicators are mainly at the level of quantitative security, and even after including quality security, ecological and market security, they are only analyzed at the national macro level, and cannot be compared with other major international food producing and consuming countries. Therefore, the construction of a complete food system model is of great practical research interest. We establish the current food system with efficiency and profitability as priorities. Considering that food cannot be completely separated from other agricultural production, and that defining strict geographical areas is also its difficult, we selected three-level indicators around the boundaries of the food system, such as factors such as import and export of agricultural products, based on the Life Cycle Assessment (LCA) analysis method. Regarding the optimization of the food system with the priority of equity and sustainability, we select two developed countries, the United Kingdom and the United States, and two developing countries, China and India.
\end{abstract}

Keywords: Food System; Life Cycle Assessment; Incentive Control Model.

\section{Introduction}

\subsection{Background}

The food system is a complex social system that relates to various aspects of food production, transportation, storage, processing, and marketing, and is non-linear, high order, and dynamic in nature. Regulating the contradiction between food production and demand and meeting the food demand of the residents is an eternal challenge. At present, international studies on food security evaluation indicators are mainly at the level of quantitative security, and even after incorporating quality security, ecological and market security, they are only analyzed at the national macro level, and cannot be compared with other major international food producing and consuming countries. Therefore, the construction of a sufficiently robust food system model is of great relevance for research.

\subsection{Signs and Definitions}

Table 1. Signs and Definitions

\begin{tabular}{|c|c|c|c|}
\hline Signs & Definitions & Signs & Definitions \\
\hline $\boldsymbol{a}_{\boldsymbol{j} \boldsymbol{i}}$ & $\begin{array}{c}\text { The impact of metrics on the } \\
\text { system }\end{array}$ & $y_{i}\left(t_{k}\right)$ & Primary scores for countries \\
\hline$\lambda_{\boldsymbol{m a x}}$ & Eigenvalue of maximum & $X_{i j}\left(t_{k}\right)$ & $\begin{array}{c}\text { Observations of the } i \text { th evaluated object on } \\
\text { indicator } X_{j} \text { at moment } t_{k}\end{array}$ \\
\hline $\mathrm{CI}$ & Coincidence indicator & $\mathrm{V}_{\mathrm{i}}^{+}\left(\mathrm{t}_{\mathrm{k}}\right)$ & Excellent incentive volume \\
\hline$\lambda_{\boldsymbol{m a x}}^{\prime}$ & $\begin{array}{c}\text { The average value of the largest } \\
\text { eigenroots }\end{array}$ & $\mathrm{V}_{\mathrm{i}}^{-}\left(\mathrm{t}_{\mathrm{k}}\right)$ & Bad incentive amount \\
\hline $\mathrm{CR}$ & Consistency ratio & $\eta$ & tone-up \\
\hline
\end{tabular}

\subsection{Assumptions and Justifications}

1. Assume that the effects of inflation are not considered. Inflation will cause the devaluation of a country's currency, and a large export surplus in international trade for a long time will adversely affect food imports and exports. 
2. Assume that the quantitative indicators of equity can basically reflect the situation of equity. Equity contains a wide range of aspects, and the quantification of indicators is more difficult.

3 . Assume that the role of the new crown epidemic is not considered. The impact of the new crown epidemic on society is complex and difficult to quantify and study.

\section{Establishment and Optimization of Food Evaluation Models}

Life cycle assessment (LCA) is an analytical method for assessing the life cycle of a resource. Consumption and environmental burden associated with a product, process or environment (ISO, 1997), LCA provides a systems-based approach to material accounting. Energy inputs and outputs in all phases of the life cycle include: raw material acquisition, production, processing, packaging, use and end-of-life recycling [1]. This is a relatively complete process.

\subsection{Definition and Selection of Indicators}

We first extracted four indicators based on the topic, namely efficiency, profitability, sustainability and equity, defining these four indicators as primary indicators. Since food cannot be completely separated from other agricultural production and it is also difficult to define strict geographical areas, we have defined the boundaries around the food system, such as imports and exports of agricultural products, agricultural trade ratios, and fuel inputs such as fossil fuels, which are also factors to be considered in a critical assessment of the food system. Therefore, we defined these data as three-level indicators by finding information and data, and organized and summarized them, which are shown in Figure 1 below.

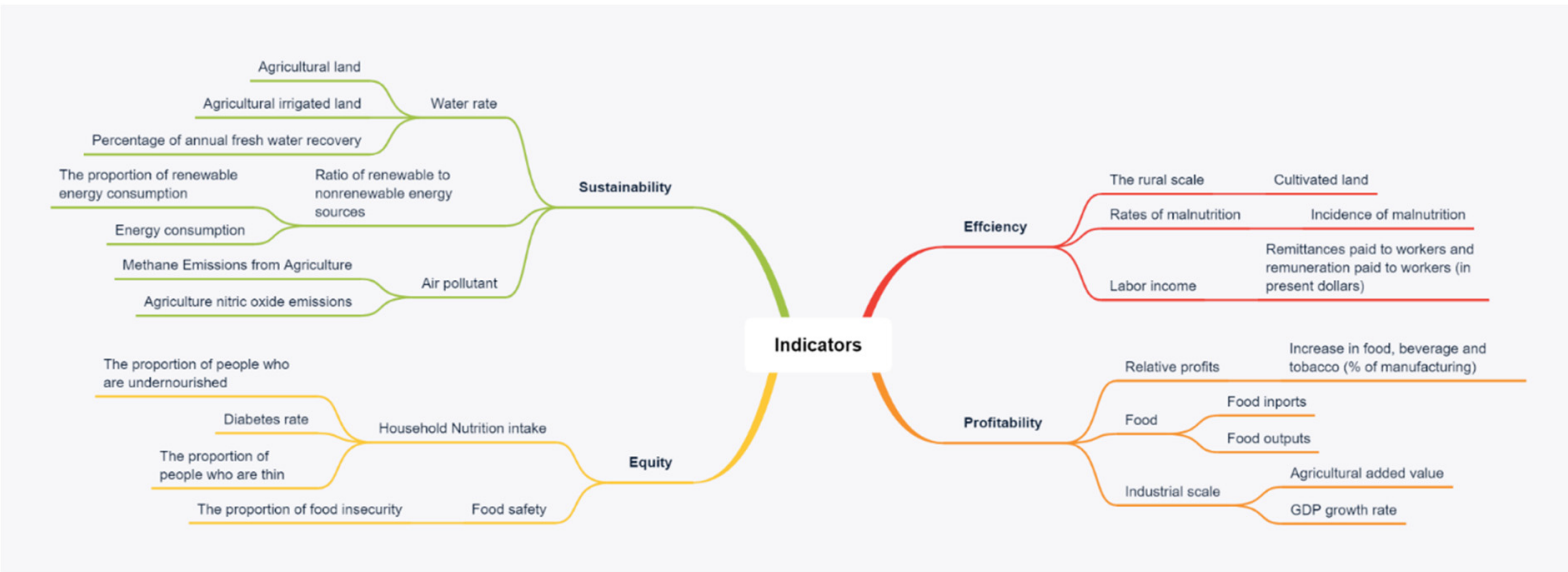

Figure 1. Assessing the indicators of the food system

\subsection{Determination of Indicator Weights}

We organize and summarize the index data, apply the polynomial fitting method to compensate for the small amount of missing data, and then perform the dimensional processing on the data, the formula is

$$
y_{i j}=\frac{x_{j}}{\sqrt{\sum_{i=1}^{n}\left(x_{i j}^{2}\right)}}
$$

The combined average of each tertiary indicator was derived, and the data from these tertiary indicators were integrated into secondary indicators.

\subsubsection{Constructing the Judgment Matrix}

Now we want to compare the influence size of four primary indicators on the $Z$ factor of the food system, we take the approach of comparing two factors to establish a pairwise comparison matrix, 
that is, two factors $\mathrm{x}_{\mathrm{i}}$ and $\mathrm{x}_{\mathrm{j}}$ are selected each time, and the ratio of the influence size of $\mathrm{x}_{\mathrm{i}}$ and $\mathrm{x}_{\mathrm{j}}$ on $Z$ is expressed by $a_{i j}$, and all the comparison results are expressed by the matrix $A=\left(a_{i j}\right)_{n x n}$, which is called $A$ as the judgment matrix between $Z$-X. It is easy to see that if the ratio of the influence of $\mathrm{xi}_{\mathrm{i}}$ and $x_{j}$ on $Z$ is $a_{i j}$, the ratio of the influence of $x_{i}$ and $x_{j}$ on $Z$ should be

$$
a_{j i}=\frac{1}{a_{i j}}
$$

For determining the value of $a_{j i}$, we cite the numbers 1 to 9 and their reciprocals as scales. For the meaning of the scales $1 \sim 9$, see Table 2 below.

Table 2. Meaning of scales

\begin{tabular}{|c|c|}
\hline Scale & Indicates that two factors are of equal importance compared to each other \\
\hline 1 & $\begin{array}{c}\text { Meaning } \\
\text { factors }\end{array}$ \\
\hline 3 & $\begin{array}{c}\text { Indicates that the former is slightly more important than the latter when compared to the two } \\
\text { two factors }\end{array}$ \\
\hline 5 & $\begin{array}{c}\text { Indicates that the former is more strongly important than the latter when compared to the two } \\
\text { factors }\end{array}$ \\
\hline 9 & $\begin{array}{c}\text { Indicates that the former is more extremely important than the latter when compared to the two } \\
\text { factors }\end{array}$ \\
\hline $2,4,6,8$ & Indicates the middle value of the above adjacent judgments \\
\hline Countdown & $\begin{array}{c}\text { If the ratio of the importance of factor } \mathrm{i} \text { to } \mathrm{j} \text { is } \boldsymbol{a}_{\boldsymbol{j}}, \text { then the ratio of the importance of factor } \mathrm{j} \text { to } \\
\text { factor } \mathrm{i} \text { is } \boldsymbol{a}_{\boldsymbol{j} i}=\mathbf{1} / \boldsymbol{a}_{\boldsymbol{i j}}\end{array}$ \\
\hline
\end{tabular}

Since efficiency and profitability are defined as the more important indicators in the current system, the scales of efficiency and profitability are set to be greater than 1 for comparing sustainability and fairness, respectively.

\subsubsection{Hierarchical Single Ranking and Consistency Test}

The judgment matrix $\mathrm{A}$ corresponds to the eigenvector $\mathrm{W}$ with the maximum eigenvalue $\lambda_{\max }$, which is normalized to the relative importance of the corresponding factor at the same level for a factor at the previous level, i.e., a single ranking of the levels.

The consistency test steps for the judgment matrix are:

Step1 Calculate consistency metrics CI.

$$
\mathrm{CI}=\frac{\lambda_{\max }-n}{n-1}
$$

Step 2 Find the corresponding average random consistency index RI. For $n=1, \ldots, 9$, the values of RI are shown in Table 3 below.

Table 3. Values of RI

\begin{tabular}{|c|c|c|c|c|c|c|c|c|c|}
\hline $\mathrm{n}$ & 1 & 2 & 3 & 4 & 5 & 6 & 7 & 8 & 9 \\
\hline $\mathrm{RI}$ & 0 & 0 & 0.58 & 0.90 & 1.12 & 1.24 & 1.32 & 1.41 & 1.45 \\
\hline
\end{tabular}

Find the average value of the maximum characteristic $\operatorname{root} \lambda_{\max }^{\prime}$, and define

$$
\mathrm{RI}=\frac{\lambda_{\max }^{\prime}-n}{n-1}
$$


Volume 15 (2021)

Step3 Calculation of consistency ratio CR

$$
\mathrm{CR}=\frac{C I}{R I}
$$

When $\mathrm{CR}<0.10$, the consistency of the judgment matrix is considered acceptable; otherwise, it is necessary to make appropriate modifications to the judgment matrix.

\subsubsection{Hierarchical Total Ranking and Consistency Test}

From the above method, the weight vector of a set of elements to an element in the upper level can be obtained, and we finally want to get the ranking weight of each element to the target, i.e., the score of the country, to make the scheme selection.

The primary score of the country is

$$
y_{i}\left(t_{k}\right)=\sum_{j=1}^{m} b_{i j} a_{j}, i=1, \ldots, n
$$

where $a_{1}, \ldots, a_{m}$ are the $m$ elements contained in the first level, and the second level contains $\mathrm{n}$ factors about the first level single ranking weights are $b_{1 j}, \ldots, b_{n j}$ respectively.

A consistency test is also required for the hierarchical total ranking, and when $\mathrm{CR}<0.10$, the results of the hierarchical total ranking are considered to have a more satisfactory consistency and the results of the analysis are accepted.

\subsection{Food System Optimization}

The above mentioned current food system is optimized, and sustainability and fairness are defined as more important indicators, so the scales of sustainability and fairness are set to be greater than 1 for comparing efficiency and profitability, respectively.

The traditional comprehensive evaluation mainly examines the comprehensive evaluation value of the evaluated object at a certain point of time, i.e., static evaluation under a certain time crosssection, but in the actual evaluation, the comprehensive evaluation value of a large number of evaluated objects in a continuous period of time is needed [2].

Therefore, we establish a dynamic comprehensive evaluation method.

\subsubsection{Create Timing Stereo Data Sheets}

With $\mathrm{n}$ evaluated objects, $\mathrm{m}$ evaluation indicators, $X_{i j}\left(t_{k}\right)$ is the observation value of the $I$ $(i=1,2, \ldots, \mathrm{n})$ evaluated object at the $t_{k}(\mathrm{k}=1,2, \ldots, \mathrm{T})$ moment about the indicator $X_{j}(\mathrm{j}=1,2, \ldots, \mathrm{m})$, so that a set of flat data table discharged in time order constitutes a three-dimensional time order data table, as shown in Table 4 below.

Table 4. Stereotime sequence data table

\begin{tabular}{|c|c|c|c|c|}
\hline & $\boldsymbol{t}_{\mathbf{1}}$ & $\boldsymbol{t}_{\mathbf{2}}$ & $\ldots$ & $\boldsymbol{t}_{\boldsymbol{T}}$ \\
\hline & $x_{1}, x_{2}, \ldots, x_{m}$ & $x_{1}, x_{2}, \ldots, x_{m}$ & $\ldots$ & $x_{1}, x_{2}, \ldots, x_{m}$ \\
\hline $\boldsymbol{s}_{\mathbf{1}}$ & $x_{11}\left(t_{1}\right), x_{12}\left(t_{1}\right), \ldots, x_{1 m}\left(t_{1}\right)$ & $x_{11}\left(t_{2}\right), x_{12}\left(t_{2}\right), \ldots, x_{1 m}\left(t_{2}\right)$ & $\ldots$ & $x_{11}\left(t_{T}\right), x_{12}\left(t_{T}\right), \ldots, x_{1 m}\left(t_{T}\right)$ \\
\hline $\boldsymbol{s}_{\mathbf{2}}$ & $x_{21}\left(t_{1}\right), x_{22}\left(t_{1}\right), \ldots, x_{2 m}\left(t_{1}\right)$ & $x_{21}\left(t_{2}\right), x_{22}\left(t_{2}\right), \ldots, x_{2 m}\left(t_{2}\right)$ & $\ldots$ & $x_{21}\left(t_{T}\right), x_{22}\left(t_{T}\right), \ldots, x_{2 m}\left(t_{T}\right)$ \\
\hline$\ldots$ & $\ldots$ & $\ldots$ & $\ldots$ & \\
\hline $\boldsymbol{s}_{\boldsymbol{n}}$ & $x_{n 1}\left(t_{1}\right), x_{n 2}\left(t_{1}\right), \ldots, x_{n m}\left(t_{1}\right)$ & $x_{n 1}\left(t_{2}\right), x_{n 2}\left(t_{2}\right), \ldots, x_{n m}\left(t_{2}\right)$ & $\ldots$ & $x_{n 1}\left(t_{T}\right), x_{n 2}\left(t_{T}\right), \ldots, x_{n m}\left(t_{T}\right)$ \\
\hline
\end{tabular}

\subsubsection{Constructing an Incentive Control Model}

The original data are processed consistently and quantitatively steeled, and note $y_{i}\left(t_{k}\right)$ as the static comprehensive evaluation value of the $i(i=1,2, \ldots, n)$ th evaluation object at the moment of $t_{k}$ $(k=1,2, \ldots, \mathrm{T})$, in order to incentivize the gain level of the evaluated object, the incentive control model needs to be constructed, that is, the cost is The original value, the benefit is the change amount, the good is the superior incentive factor, the bad is the inferior incentive factor. In order to incentivize 
the gain level of the evaluated object, it is necessary to construct the incentive control model, for an evaluated object, it gets the superior incentive amount as

$$
V_{i}^{+}\left(t_{k}\right)= \begin{cases}y_{i}^{+}\left(t_{k}\right)-y_{i}\left(t_{k}\right) & y_{i}^{+}\left(t_{k}\right)>y_{i}\left(t_{k}\right) \\ 0 & \text { other }\end{cases}
$$

The amount of poor incentive is $V_{i}^{-}\left(t_{k}\right)= \begin{cases}y_{i}\left(t_{k}\right)-y_{i}^{-}\left(t_{k}\right) & y_{i}\left(t_{k}\right)>y_{i}^{-}\left(t_{k}\right) \\ 0 & \text { other }\end{cases}$

The average maximum gain, average minimum gain and average gain of the evaluated object are called $\eta^{\max }, \eta^{\min }, \bar{\eta}$ respectively, and the formula is

$$
\left\{\begin{array}{l}
\eta^{\max }=\max \frac{1}{T-1} \sum_{K=1}^{T-1}\left(y_{i}\left(t_{k-1}\right)-y_{i}\left(t_{k}\right)\right) \\
\eta^{\min }=\min \frac{1}{T-1} \sum_{K=1}^{T-1}\left(y_{i}\left(t_{k-1}\right)-y_{i}\left(t_{k}\right)\right) \\
\bar{\eta}=\frac{1}{n(T-1)} \sum_{i=1}^{n} \sum_{K=1}^{T-1}\left(y_{i}\left(t_{k-1}\right)-y_{i}\left(t_{k}\right)\right)
\end{array}\right.
$$

$\eta^{+}, \eta^{-}$is the gain level of the evaluated object, and its formula is

$$
\left\{\begin{array}{c}
\eta^{+}=\bar{\eta}+\left(\eta^{\max }-\bar{\eta}\right) k^{+} \\
\eta^{-}=\bar{\eta}-\left(\bar{\eta}-\eta^{\min }\right) k^{-}
\end{array}\right.
$$

where $k^{+}, k^{-}$are the corresponding floating coefficients, $\mathrm{k}^{+}, \mathrm{k}^{-} \epsilon[0,1]$, at which time the superior and inferior excitation points can be found by means of backpropagation $y_{i}^{+}\left(t_{k}\right), y_{i}^{-}\left(t_{k}\right)$.

\section{Application of the Model}

The difference between the two systems can be known by applying the two models, the established model and the optimized model, to developed and developing countries respectively. To avoid chance, we choose two developed countries, UK and USA, and two developing countries, China and India, for specific research discussion.

\subsection{Application of Pre-optimization Models in the Country}

We use the LCA food system established by the previous 2.1 and 2.2 to first organize and summarize the index data, apply the polynomial fitting method to make up for the small amount of missing data, then dimensionalize the data and find out the comprehensive average of each tertiary index, and integrate the data of these tertiary indexes into secondary indexes. The data of these threelevel indicators are then integrated into two-level indicators, and then a comprehensive indicator of cost and benefit is integrated into the first-level indicator by using the dimensionless secondary indicators, and taking sustainability as an example, the formula is

$$
\rho_{3}=\frac{\frac{\rho_{a l}+\rho_{a i}+\rho_{a t}}{3}+\frac{\rho_{r e}+\rho_{e c}}{2}+\frac{\rho_{N O}+\rho_{C H 4}}{2}}{3}
$$

Which $\rho_{a l}$ is Agricultural land, $\rho_{a i}$ is Agricultural irrigated land, $\rho_{a t}$ is Percentage of annual fresh water recovery, $\rho_{r e}$ is The proportion of renewable energy consumption, $\rho_{e c}$ is Energy 
consumption, $\rho_{N O}$ is Methane Emissions from Agriculture, $\rho_{C H 4}$ is Agricultural nitric oxide emissions.

The weights of the country primary scores were also calculated using hierarchical analysis. The judgment matrix when efficiency and profitability are considered as priorities is constructed as shown in Table 5 below.

Table 5. Judgment matrix with efficiency and profitability as priorities

\begin{tabular}{|c|c|c|c|c|}
\hline & Efficiency & Profitability & Sustainability & Fairness \\
\hline Efficiency & 1 & $1 / 2$ & 3 & 5 \\
\hline Profitability & 2 & 1 & 4 & 6 \\
\hline Sustainability & $1 / 3$ & $1 / 4$ & 1 & 2 \\
\hline Fairness & $1 / 5$ & $1 / 6$ & $1 / 2$ & 1 \\
\hline
\end{tabular}

The weights of the four first-level indicators obtained from the above judgment matrix are shown in Table 6 below.

Table 6. Weights of the four first-level indicators before optimization

\begin{tabular}{|c|c|c|c|c|}
\hline Tier 1 Indicators & Efficiency & Profitability & Sustainability & Fairness \\
\hline Weighting & 0.3135 & 0.4967 & 0.1213 & 0.0685 \\
\hline
\end{tabular}

A consistency test was performed on the hierarchical total ranking, and when $\mathrm{CR}<0.10$, the results of the hierarchical total ranking were considered to have a more satisfactory consistency and the results of this analysis were accepted. The test yielded $\mathrm{CR}=0.0126$, which satisfied the above condition.

The evaluation values for each year for the UK, US, China and India were obtained from the weights combined with the LCA food system as shown in Table 7 below.

Table 7. Valuation of countries before optimization 2009-2019

\begin{tabular}{|c|c|c|c|c|c|c|c|c|c|c|c|c|}
\hline & 2009 & 2010 & 2011 & 2012 & 2013 & 2014 & 2015 & 2016 & 2017 & 2018 & 2019 \\
\hline \multirow{2}{*}{ China } & 0.717 & 0.776 & 0.818 & 0.8709 & 0.92925 & 0.9902 & 1.04007 & 1.14962 & 1.19704 & 1.15590 & 1.20431 \\
& 7580 & 0106 & 3521 & 598 & 363 & 893 & 158 & 575 & 873 & 33 & 303 \\
\hline \multirow{2}{*}{ US } & 0.733 & 0.803 & 0.844 & 0.8913 & 0.93988 & 0.9911 & 1.05026 & 1.10763 & 1.16751 & 1.21255 & 1.25978 \\
& 2394 & 9004 & 8968 & 143 & 692 & 755 & 848 & 208 & 188 & 83 & 652 \\
\hline \multirow{2}{*}{ UK } & 0.721 & 0.781 & 0.828 & 0.8803 & 0.93399 & 0.9903 & 1.05243 & 1.17451 & 1.15110 & 1.20411 & 1.25621 \\
& 5366 & 7044 & 4662 & 764 & 361 & 933 & 735 & 311 & 846 & 78 & 710 \\
\hline \multirow{2}{*}{ India } & 0.707 & 0.768 & 0.823 & 0.8785 & 0.93604 & 0.9904 & 1.06057 & 1.10804 & 1.17197 & 1.23648 & 1.28011 \\
& 5266 & 4441 & 0763 & 202 & 664 & 824 & 885 & 348 & 444 & 96 & 226 \\
\hline
\end{tabular}

The total evaluation value for each country was obtained by cumulative summation, as shown in Table 8 below.

Table 8. Total assessed values for each country before optimization

\begin{tabular}{|c|c|c|c|c|}
\hline Country & China & Unite States & Unite Kingdom & India \\
\hline Total evaluation value & 10.8496 & 11.0022 & 10.9749 & 10.9613 \\
\hline
\end{tabular}

\subsection{Application of the Optimized Model in the Country}

The optimized food system is mainly considered with sustainability and equity as priorities. We use the optimization model established in the previous section 3.3, i.e., the dynamic comprehensive evaluation-LCA model, to first construct the judgment matrix when sustainability and fairness are considered as priorities as shown in Table 9 below. 
Table 9. Judgment matrix with sustainability and equity as priorities

\begin{tabular}{|c|c|c|c|c|}
\hline & Efficiency & Profitability & Sustainability & Fairness \\
\hline Efficiency & 1 & $1 / 2$ & $1 / 4$ & $1 / 4$ \\
\hline Profitability & 2 & 1 & $1 / 3$ & $1 / 3$ \\
\hline Sustainability & 4 & 3 & 1 & 2 \\
\hline Fairness & 4 & 3 & $1 / 2$ & 1 \\
\hline
\end{tabular}

The weights of the four first-level indicators obtained from the above judgment matrix are shown in Table 10 below.

Table 10. Weights of the four first-level indicators after optimization

\begin{tabular}{c|c|c|c|c}
\hline Tier 1 Indicators & Efficiency & Profitability & Sustainability & Fairness \\
\hline Weighting & 0.0868 & 0.142 & 0.4504 & 0.3207 \\
\hline
\end{tabular}

A consistency test was performed on the hierarchical total ranking, and when $\mathrm{CR}<0.10$, the results of the hierarchical total ranking were considered to have a more satisfactory consistency and the results of this analysis were accepted. The test yielded $\mathrm{CR}=0.0301$, which satisfied the above condition.

The evaluation values for each year for the UK, US, China and India were obtained as shown in Table 11 below.

Table 11. Optimized 2009-2019 country evaluation values

\begin{tabular}{|c|c|c|c|c|c|c|c|c|c|c|c|}
\hline & 2009 & 2010 & 2011 & 2012 & 2013 & 2014 & 2015 & 2016 & 2017 & 2018 & 2019 \\
\hline \multirow{2}{*}{ China } & 2.0445 & 2.253872 & 2.4493 & 2.653482 & 2.862586 & 3.007860 & 3.275375 & 3.525167 & 3.724954 & 3.848740 & 4.049201 \\
& 69868 & 182 & 17303 & 13 & 298 & 631 & 384 & 013 & 941 & 252 & 439 \\
\hline \multirow{2}{*}{ US } & 2.0559 & 2.276074 & 2.4703 & 2.669245 & 2.869991 & 3.144645 & 3.282482 & 3.490757 & 3.701081 & 3.898815 & 4.098210 \\
& 75795 & 772 & 04948 & 383 & 497 & 215 & 009 & 185 & 21 & 951 & 558 \\
\hline \multirow{2}{*}{ UK } & 2.0454 & 2.256853 & 2.4559 & 2.659471 & 2.864629 & 3.008985 & 3.283895 & 3.548680 & 3.687208 & 3.891781 & 4.095425 \\
& 5380 & 20 & 9089 & 68 & 71 & 84 & 24 & 775 & 477 & 979 & 666 \\
\hline \multirow{2}{*}{ India } & 2.0339 & 2.246035 & 2.4516 & 2.658272 & 2.866483 & 3.012017 & 3.291191 & 3.491668 & 3.705356 & 3.919264 & 4.115803 \\
& 68247 & 54 & 35129 & 944 & 575 & 098 & 591 & 993 & 278 & 034 & 891 \\
\hline
\end{tabular}

The total evaluation value for each country is obtained by cumulative summation, as shown in Table 12 below.

Table 12. Total evaluation value of each country after optimization

\begin{tabular}{|c|c|c|c|c|}
\hline Country & China & US & UK & India \\
\hline Total evaluation value & 33.6951 & 33.9576 & 33.7984 & 33.7917 \\
\hline
\end{tabular}

\section{Summary}

\subsection{Strengths}

1. Combining the life-cycle method system and defining the indicators of the system independently and innovatively to evaluate the food system of each country.

2. The dynamic comprehensive evaluation is carried out by means of incentive of superior and inferior gain levels, which fully takes into account the dynamic development level of the evaluated object and can play a motivating and guiding role in the development of the evaluated object, and can be widely used in the problem of comprehensive evaluation.

\subsection{Weaknesses}

1. The hierarchical analysis method to determine the weights is highly subjective, which may have some influence on the results.

2. For the life cycle assessment system, the few indicators selected in this paper may not be able to fully translate the real situation of the food system. 


\section{Acknowledgments}

The work is supported in part by the Science and Technology Plan of Beijing Municipal Education Commission under Grant KM (No. 202110017002).

\section{References}

[1] Martin C Heller,Gregory A Keoleian. Assessing the sustainability of the US food system: a life cycle perspective [J]. Agricultural Systems,2003,76(3).

[2] Ma Zanfu, Guo Yajun, Zhang Faming, Pan Yuhou. A Dynamic Comprehensive Evaluation Method Based on Gain Level Excitation [J].Journal of Systems Engineering,2009,24(02):243-247.

[3] $\mathrm{Hu}$ Yuhong. Correct understanding of the principle of social justice in the protection of the rights of the weak [J]. Legal Studies,2015(01):91-102.

[4] Hamid El Bilali. Transition heuristic frameworks in research on agro-food sustainability transitions[J]. Environment, Development and Sustainability,2020,22(3).

[5] E. Gunilla Almered Olsson. Urban food systems as vehicles for sustainability transitions[J]. Bulletin of Geography. Socio-economic Series,2018,40(40).

[6] Guo Yajun. A new dynamic and comprehensive evaluation method [J]. Journal of Management Science, 2002 (02):49-54. 